\title{
Co-circulation of multiple subtypes of enterovirus A71 (EV- A71) genotype C, including novel recombinants characterised by use of whole genome sequencing (WGS), Denmark 2016
}

SE Midgley ${ }^{1}$, AG Nielsen ${ }^{1}$, R Trebbien ${ }^{1}$, MW Poulsen ${ }^{1}$, PH Andersen ${ }^{2}$, TK Fischer $^{13}$

1. Section for Virus Surveillance and Research, Statens Serum Institut, Copenhagen, Denmark

2. Infectious Disease Epidemiology, Statens Serum Institut, Copenhagen, Denmark

3. Center for Global Health, Department of Infectious Diseases, University of Southern Denmark, Odense, Denmark

Correspondence: Sofie Elisabeth Midgley (soi@ssi.dk)

Citation style for this article:

Midgley SE, Nielsen AG, Trebbien R, Poulsen MW, Andersen PH, Fischer TK. Co-circulation of multiple subtypes of enterovirus A71 (EV- A71) genotype C, including novel recombinants characterised by use of whole genome sequencing (WGS), Denmark 2016. Euro Surveill. 2017;22(26): pii=30565. DOI: http://dx. doi. org/10.2807/1560-7917.ES.2017.22.26.30565

Article submitted on 19 May 2017 / accepted on 29 June 2017 / published on 29 June 2017

In Europe, enterovirus A71 (EV-A71) has primarily been associated with sporadic cases of neurological disease. The recent emergence of new genotypes and larger outbreaks with severely ill patients demonstrates a potential for the spread of new, highly pathogenic EV-A71 strains. Detection and characterisation of these new emerging EV variants is challenging as standard EV assays may not be adequate, necessitating the use of whole genome analysis.

Enterovirus A71 (EV-A71) has been detected in Denmark in relatively low numbers since 2001. Of the different genotypes of EV-A71, only $B_{5}, C_{1}, C_{2}$, and $C_{4}$ have been identified [1,2]. All genotypes have been either associated with neurological symptoms, or milder hand, foot, and mouth disease (HFMD) in Denmark. EV-A71 subtype C4a, commonly circulating in Asia, has been identified as the cause of extensive outbreaks of HFMD with neurological complications and fatalities $[3,4]$. During a pilot project validating next generation sequencing (NGS) technology for full genome typing of EVs at the National World Health Organization (WHO) Reference Laboratory for Poliovirus at Statens Serum Institut (SSI), a novel EV-A71 variant was identified. This variant was shown to be genetically closely related to a recently published novel EV-A71 genotype $C_{1}$ recombinant variant identified in Germany $[5,6]$. Re-analysis of sequence data and full genome re-sequencing of selected samples from the Danish EV surveillance database revealed additional viruses phylogenetically closely related to this new variant.

\section{Laboratory analyses}

Samples included in the analysis were collected through the Danish EV surveillance system [7]. They were genotyped using VP2 and/or VP1 PCR assays
[8,9] and sequenced as described previously [2]. All 20 EV-A71 cases from 2016, as well as additional 12 historical cases previously subtyped as $C_{1}$ were analysed. NGS was carried out directly on clinical sample material, as described previously [10], for a subset of samples $(n=10)$ and one sample was characterised from cultured material obtained as part of another study. The Illumina MiSeq platform was used to generate the sequencing data that were analysed using the CLC genomics workbench. Consensus sequences were exported as fasta files, and aligned with all available full-length EV-A71 genomes downloaded from the National Center for Biotechnology Information (NCBI) GenBank using SSE v1.3[11]. Phylogenetic analysis was carried out using MEGA 6 [12], maximum likelihood with a general time reversible model, gamma distribution and invariable sites, and 1,000 bootstrap replications. Bootscanning analysis was also carried out using SimPlot v3.5.1 [13]. Sequences have been submitted to GenBank, accession numbers pending.

\section{Enterovirus A71 genotype C cases 2001-2016}

The most common sample material available for the 32 EV-71 RNA-positive patients was stool $(n=22)$ followed by vesicular fluid $(n=6)$. Other sample materials were urine, cerebrospinal fluid (CSF), respiratory secretion and biopsy. (Table 1).

Patient ages ranged from 7 days to 36 years with a median of 3 months and inter-quartile ranges of 2 and 12 months, respectively, and 11 of 32 patients were females. Clinical information was available for 23 of 32 cases, collected as part of the enhanced EV surveillance system in place [7]. Six cases had HFMD, 11 had gastrointestinal symptoms, 14 had fever, five had 
FIGURE 1

Phylogenetic analysis of enterovirus A71 genotype C cases, Denmark, 2001-2016

\section{A. Partial VP1 sequences}

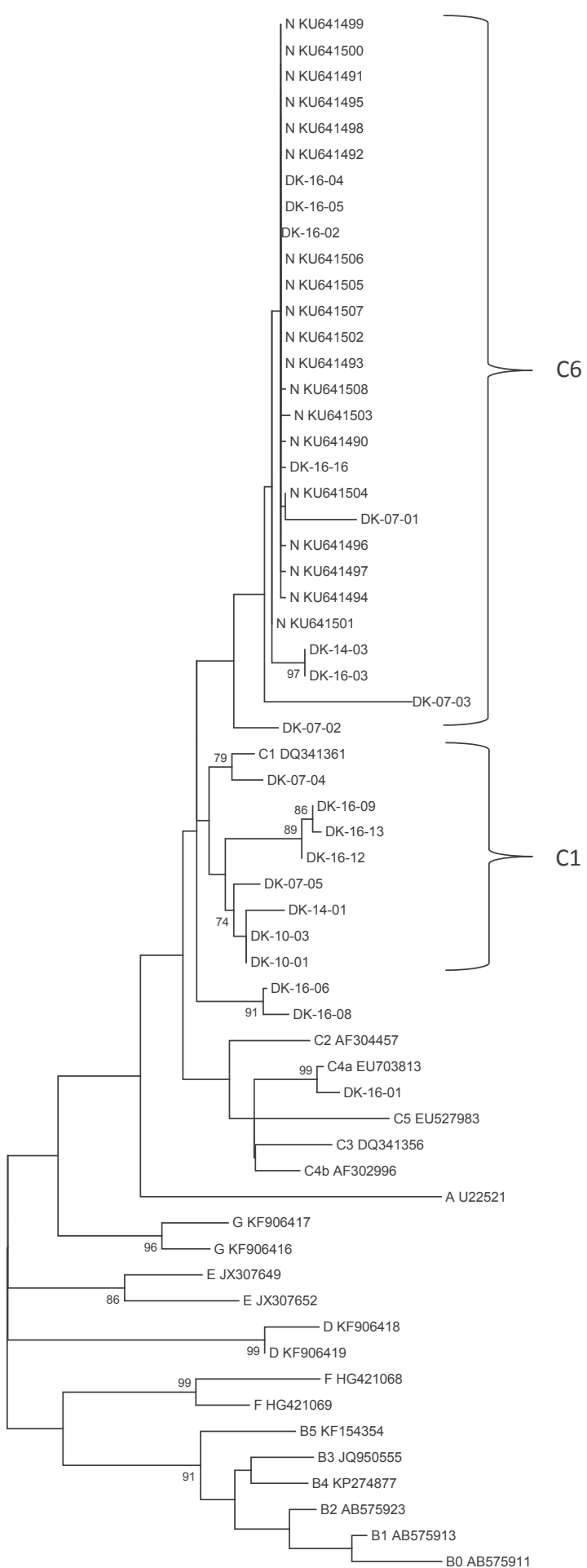

$\longmapsto 0,05$

\section{B. Partial VP2/VP4 sequences}

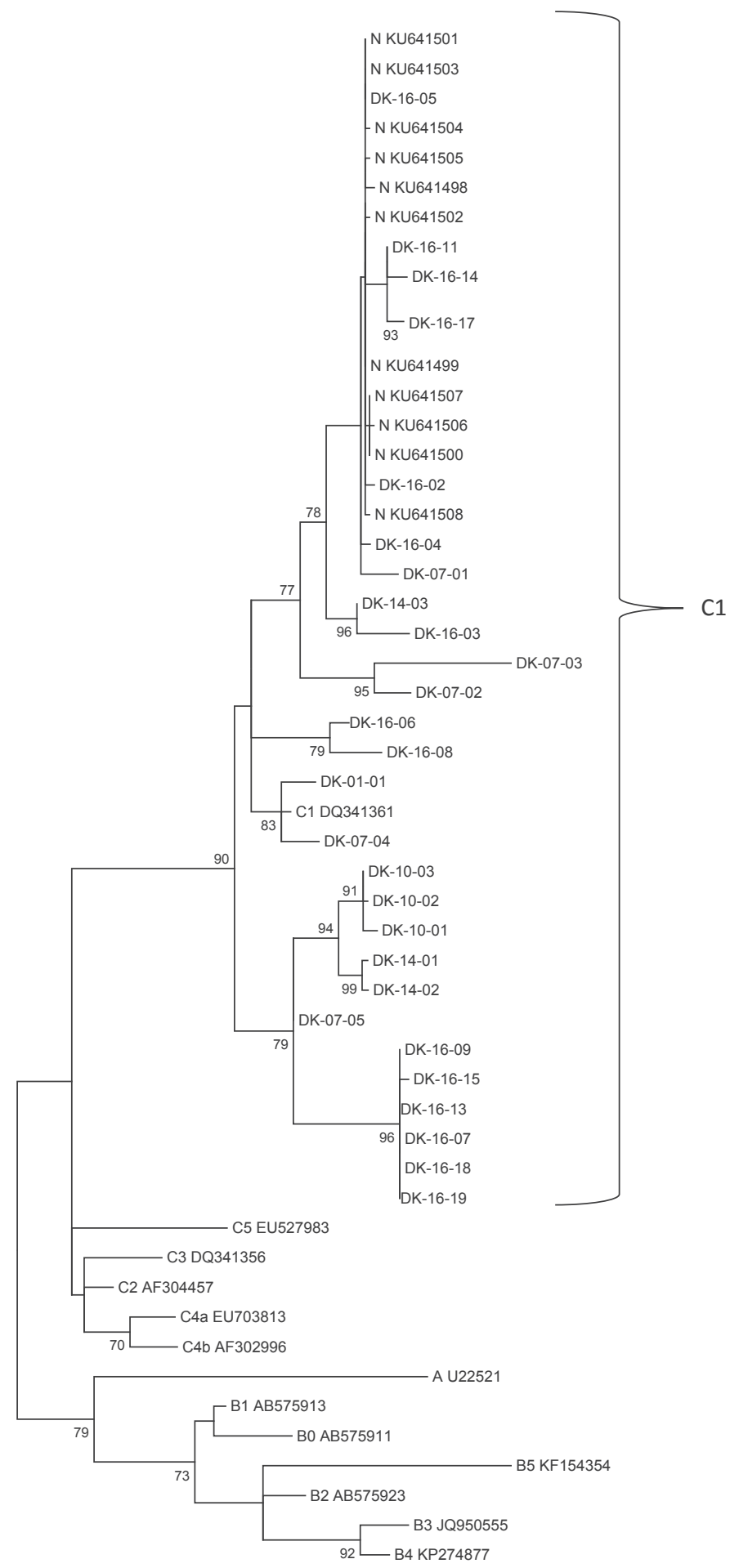

0,05

German new variant strains are identified with a capital N as a prefix, Danish strains are identified by the case ID as described in Table 1 prefixed by DK. Genotypes C 1 and C 6 are marked with brackets. Reference sequences for other genotypes are prefixed by the genotype, followed by the GenBank accession number.

Phylogenetic analysis was carried out using MEGA 6 [12], maximum likelihood with a general time reversible model, gamma distribution and invariable sites and 1,000 bootstrap replications. The bootstrap support is indicated at nodes, showing only values of $>70 \%$. The bar denotes 0.05 nt substitutions per site. 


\section{FIGURE 2}

Phylogenetic analysis of near-complete genome sequences, enterovirus A71 genotype C cases, Denmark, 2001-2016

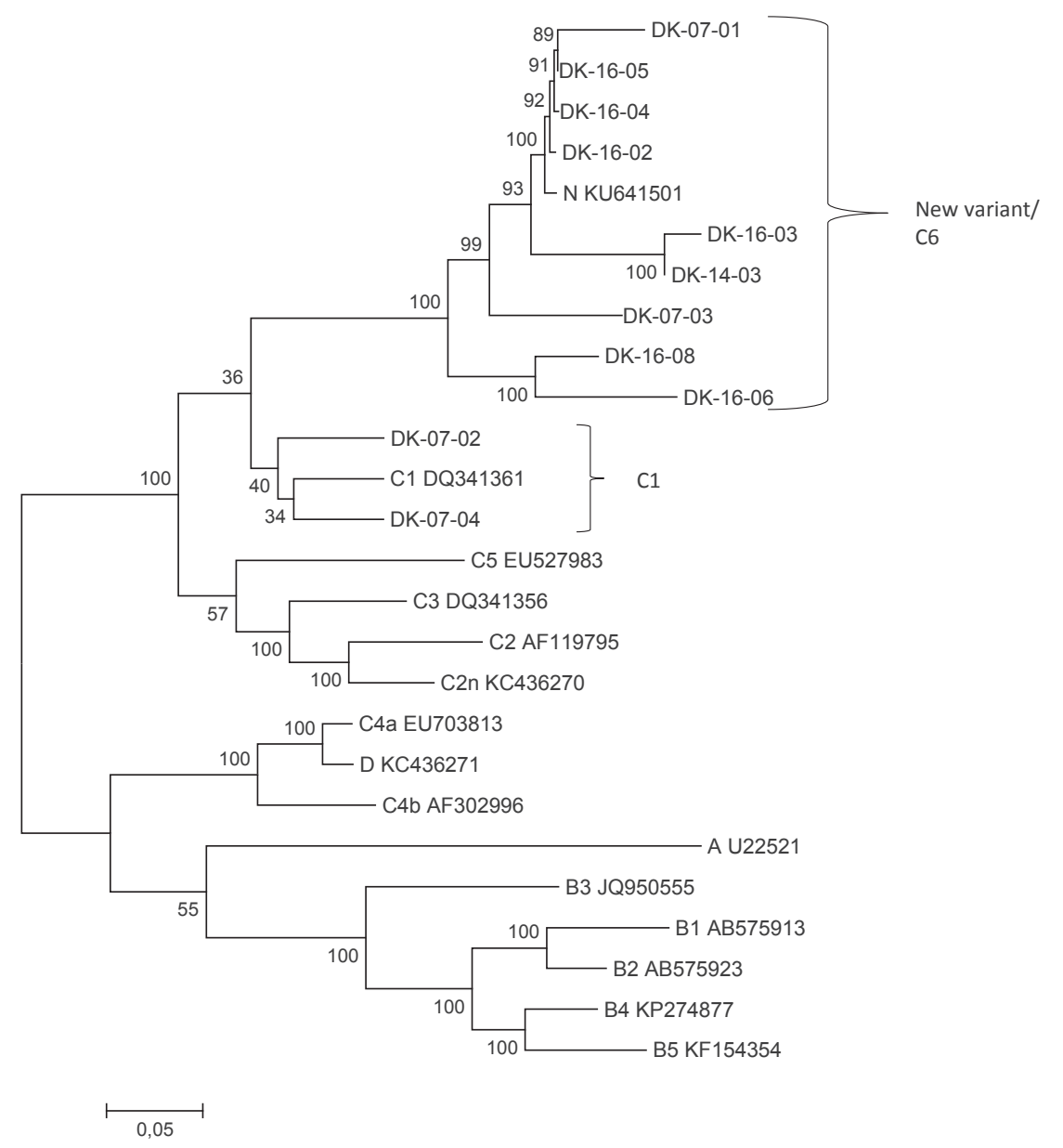

German new variant strains are identified with a capital N as a prefix, Danish strains are identified by the case ID as described in Table 1 prefixed by DK. Genotypes C 1 and C6 are marked with brackets. Reference sequences for other genotypes are prefixed by the genotype, followed by the GenBank accession number.

Phylogenetic analysis was carried out using MEGA 6 [12], maximum likelihood with a general time reversible model, gamma distribution and invariable sites, and 1,000 bootstrap replications. The bootstrap support is indicated at nodes. The bar denotes 0.05 nt substitutions per site.

central nervous system involvement (Guillain-Barré syndrome, meningitis, encephalitis), and there was one death. The death and one of the sepsis cases were associated with a bacterial co-infection (Clostridium difficile and group B Streptococcus, respectively). Hospital admission data was available for 13 cases, and the hospitalisation ranged from less than one day to 10 days (average 3.6 days, SD 2.8).

\section{Phylogenetic analysis}

Phylogenetic analysis of partial VP2/VP4 and /or VP1 sequence data showed that 17 samples could be characterised as belonging to EV-A71 genotype $C_{1}$ and 13 samples were closer to a new variant recently identified in our laboratory. Moreover, one EV-A71 genotype $C_{2}$ and one $C_{4}$ were identified (Figure 1). NGS data was obtained for a total of 11 strains, nine were found to belong to the new genotype, and two were $C_{1}$ (Figure 2).
In the VP1 and near-full genome phylogenetic analyses, the new variant forms a clade separately from other $C_{1}$ viruses. The new recombinant strain was identified in a sample dating back to 2007 . In the WGS three clades were seen: (i) one containing Danish strains from 2007 and 2016 as well as strains from Germany, (ii) one with single Danish strains from 2014 and 2016, and (iii) one with two Danish strains from 2016. There was no difference between the genotypes regarding the clinical symptoms of the cases (Table 1 ). In the VP2 analysis it was not possible to clearly distinguish between $\mathrm{C}_{1}$ and the new variant.

Bootscanning analysis showed that Danish new variants were nearly identical to the German new variants over the majority of the genome. However, there was no similarity in the 3 Dpol region, where both the German and the Danish strains differed from all published subtypes (Figure 3). The German strains appear to have a 
Bootscanning and SimPlot analysis of novel enterovirus A71 genotype C cases DK-14-03 (Denmark 2014) and KU641506 (Germany 2015)

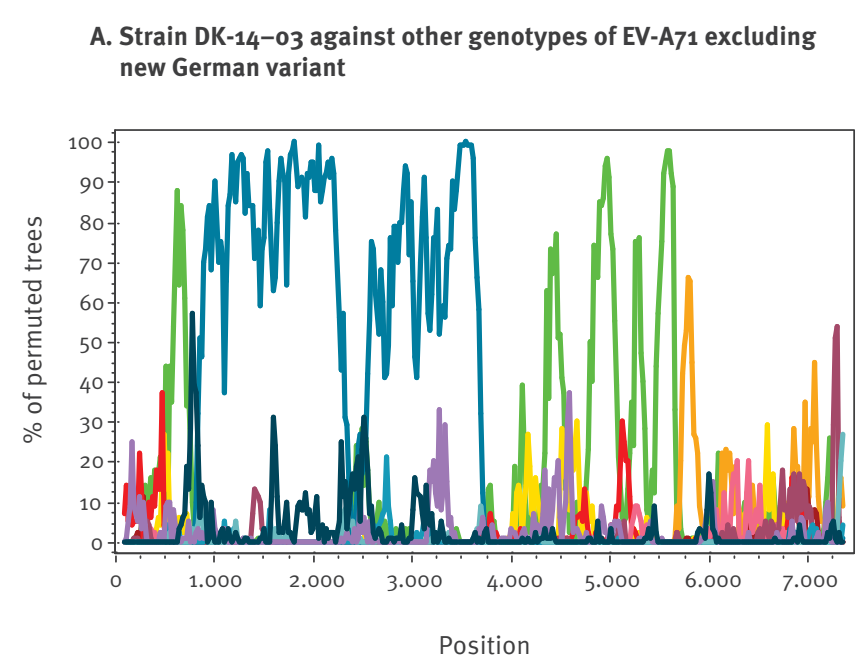

C. New German variant against other genotypes of EV-A71, excluding strain DK-14-03

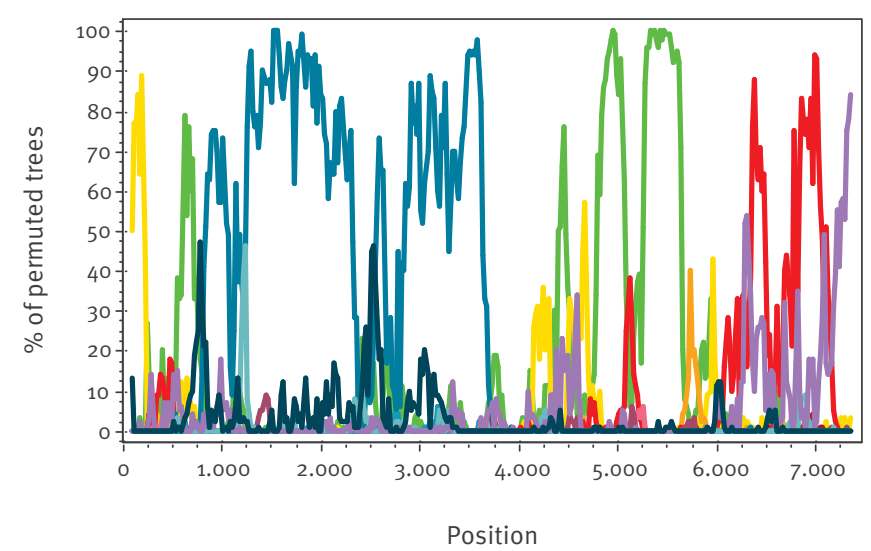

B. Strain DK-14-03 against other genotypes of EV-A71 including new German variant

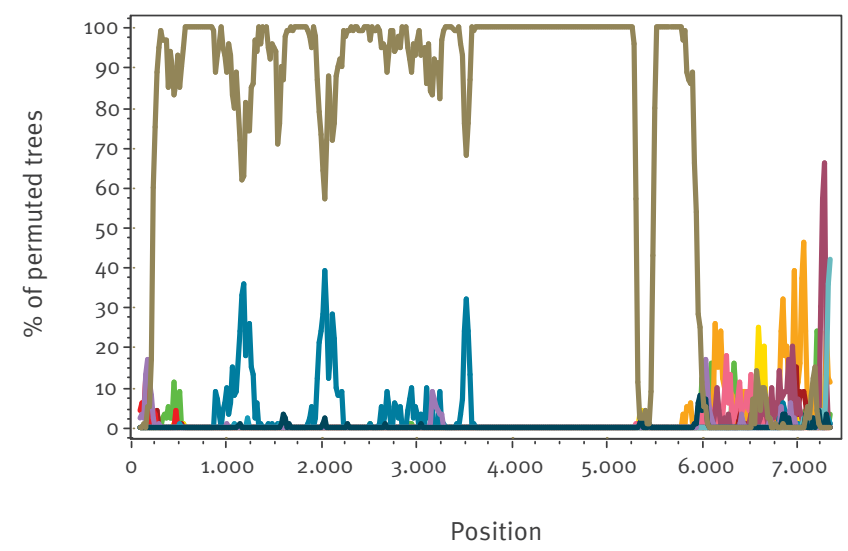

D. New German variant against other genotypes of EV-A71, including strain DK-14-03, EV-A71 genotype C cases
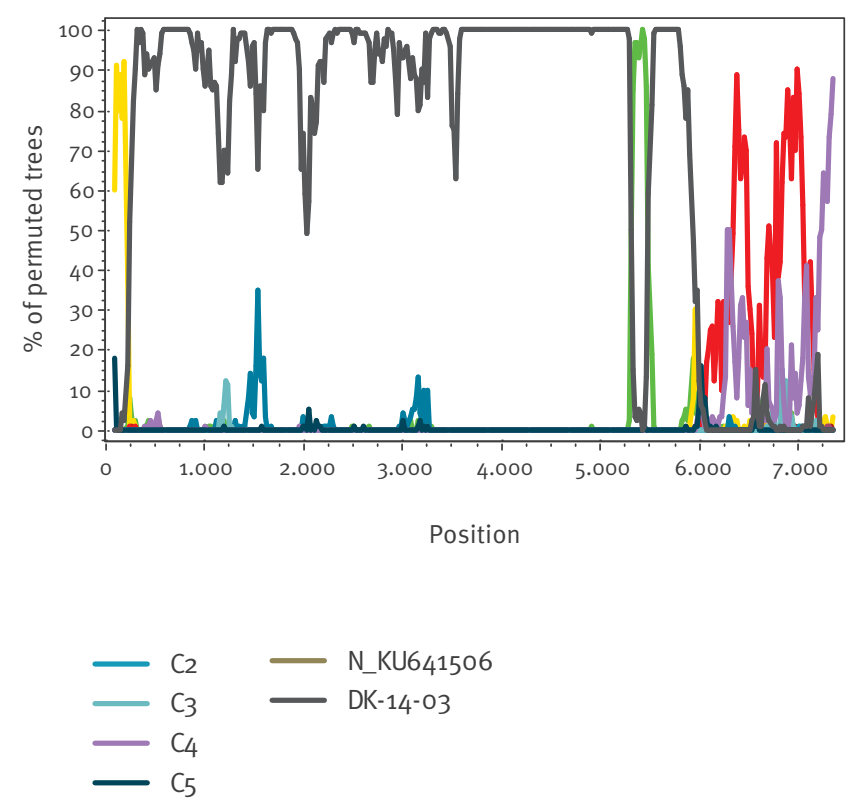

DK: Denmark; EV: enterovirus.

mosaic genome, more closely related to different genotypes in different parts of the genome. When analysed without comparison to the German strain, the Danish variant also showed a similar mosaic genome (Figure 3). Both strains appear to be closest to $C_{1}$ in the VP1 region of the genome.

\section{Discussion and conclusions}

This study documents the circulation of new emerging EV-A71 genotype C variants associated with neurologic symptoms, as well as HFMD, in the Danish population. Novel EV-A71 variants were detected with WGS, and could be traced back to the first detection in the
Danish population in 2007. Phylogenetically, a higher level of genetic variation was seen among the Danish strains as compared with the previously reported German EV-A71 $C_{1}$ variant strains $[5,6]$ suggesting that these novel variants have arisen from genetic reassortment of EV-A71 viruses over a prolonged period of time.

Three EV-A71 C variant clades were identified in Denmark one of which contains Danish EV-A71 C strains from 2007 and 2016 as well as the German 2015 strains. The phylogenetic analyses in this study show that the new variant EV-A71 sub-genotype $C$ viruses form a clade separate from the $C_{1}$ viruses, and the 
TABLE

Clinical description of enterovirus A71 genotype C cases, Denmark, 2001-2016 ( $\mathrm{n}=32)$

\begin{tabular}{|c|c|c|c|c|c|c|}
\hline $\begin{array}{l}\text { Year of } \\
\text { detection- } \\
\text { case ID }\end{array}$ & Age & Sample material & Sequence type ${ }^{a}$ & $\begin{array}{l}\text { EV-A71 } \\
\text { genotype }\end{array}$ & Symptoms & $\begin{array}{l}\text { Hospital } \\
\text { admission }\end{array}$ \\
\hline $01-01$ & $1-2$ years & Unknown & $\mathrm{VP}_{2}$ & $\mathrm{C}_{1}$ & Guillain-Barré syndrome & Unknown \\
\hline $07-01$ & $5-10$ years & Vesicular fluid & VP2,WGS & C6 & Vesicles & Unknown \\
\hline $07-02$ & $<6$ months & Stool & $\mathrm{VP}_{1}, \mathrm{VP}_{2}, \mathrm{WGS}$ & $\mathrm{C}_{1}$ & Unknown & Unknown \\
\hline $07-03$ & $<6$ months & Stool & $\mathrm{VP}_{1}, \mathrm{VP}_{2}, \mathrm{WGS}$ & $\mathrm{C} 6$ & Unknown & Unknown \\
\hline $07-04$ & $1-2$ years & Stool & $\mathrm{VP}_{1}, \mathrm{VP} 2, \mathrm{WGS}$ & $\mathrm{C}_{1}$ & $\begin{array}{c}\text { Diarrhoea for } 3 \text { weeks after } \\
\text { travelling }\end{array}$ & Unknown \\
\hline $07-05$ & $<6$ months & Stool and urine & $V P_{1}, V_{2}$ & $\mathrm{C}_{1}$ & Meningitis, fever, abdominal pain & Unknown \\
\hline $10-01$ & $35-40$ years & Vesicular fluid & $\mathrm{VP}_{1}, \mathrm{VP}_{2}$ & $\mathrm{C}_{1}$ & HFMD- rash, vesicles & «1 day \\
\hline $10-02$ & $0-2$ months & Stool & $\mathrm{VP} 2$ & $\mathrm{C}_{1}$ & $\begin{array}{c}\text { Sepsis - fever }>38.5 \text {, diarrhoea, } \\
\text { vomiting blood }\end{array}$ & 5 days \\
\hline $10-03$ & $0-2$ months & Stool and CSF & $V P_{1}, V_{2}$ & $\mathrm{C}_{1}$ & Meningitis & Unknown \\
\hline $14-01$ & $25-30$ years & Vesicular fluid & $\mathrm{VP}_{1}, \mathrm{VP}_{2}$ & $\mathrm{C}_{1}$ & HFMD - rash, vesicles & No \\
\hline $14-02$ & $1-2$ years & $\begin{array}{l}\text { Respiratory } \\
\text { secretion }\end{array}$ & $\mathrm{VP} 2$ & $\mathrm{C}_{1}$ & Respiratory symptoms & Unknown \\
\hline $14-03$ & $<6$ months & Unknown & $\mathrm{VP}_{1}, \mathrm{VP}_{2}, \mathrm{WGS}$ & C6 & Fever $>38.5^{\circ} \mathrm{C}$, diarrhoea, vomiting & 1 day \\
\hline $16-01$ & $<6$ months & $\begin{array}{c}\text { Small intestine } \\
\text { biopsy }\end{array}$ & $\mathrm{VP} 1$ & $\mathrm{C}_{4}$ & $\begin{array}{c}\begin{array}{c}\text { Sudden death, also Clostridium } \\
\text { difficile infection }\end{array} \\
\end{array}$ & Unknown \\
\hline $16-02$ & $<6$ months & Stool & $\mathrm{VP}_{1}, \mathrm{VP}_{2}, \mathrm{WGS}$ & $\mathrm{C} 6$ & Fever $>38.5^{\circ} \mathrm{C}$, diarrhoea, rash & 1 day \\
\hline $16-03$ & $1-2$ years & Vesicular fluid & $\mathrm{VP} 2, \mathrm{WGS}$ & $\mathrm{C6}$ & HFMD - rash, vesicles & no \\
\hline $16-04$ & $<6$ months & Stool & $\mathrm{VP}_{1}, \mathrm{VP}_{2}, \mathrm{WGS}$ & $\mathrm{C} 6$ & Fever $>38.5^{\circ} \mathrm{C}$, diarrhoea, rash & $\ll 1$ day \\
\hline $16-05$ & $6-11$ months & Stool & $\mathrm{VP}_{1}, \mathrm{VP} 2, \mathrm{WGS}$ & C6 & $\begin{array}{l}\text { HFMD }- \text { fever }>38.5^{\circ} \mathrm{C} \text {, rash, } \\
\text { vesicles, vomiting }\end{array}$ & 6 days \\
\hline $16-06$ & $<6$ months & Stool & $\mathrm{VP}_{1}, \mathrm{VP} 2, \mathrm{WGS}$ & $\mathrm{C}$ new/C6 ${ }^{\mathrm{b}}$ & $\begin{array}{c}\text { HFMD - fever }>38.5^{\circ} \mathrm{C} \text {, rash, } \\
\text { vesicles, respiratory symptoms }\end{array}$ & 4 days \\
\hline $16-07$ & $<6$ months & Stool & $\mathrm{VP}_{2}$ & $\mathrm{C}_{1}$ & $\begin{array}{l}\text { Encephalitis - fever }>38.5^{\circ} \mathrm{C}, \\
\text { abnormal sensitivity to stimuli, } \\
\text { diarrhoea, rash, respiratory } \\
\text { symptoms, sepsis-like symptoms }\end{array}$ & 5 days \\
\hline $16-08$ & $4-5$ years & Stool & $\mathrm{VP}_{2}, \mathrm{WGS}$ & $\mathrm{C}$ new/C6 ${ }^{\mathrm{b}}$ & $\begin{array}{l}\text { Meningitis -neck stiffness, } \\
\text { affected consciousness, fever, } \\
\text { rash, vomiting }\end{array}$ & 5 days \\
\hline $16-09$ & $<6$ months & Stool & $\mathrm{VP}_{1}, \mathrm{VP}_{2}$ & $\mathrm{C}_{1}$ & Unknown & Unknown \\
\hline $16-10$ & $1-2$ years & Stool & $\mathrm{VP}_{1}$ & $\mathrm{C}_{1}$ & Unknown & Unknown \\
\hline $16-11$ & $1-2$ years & Stool & $\mathrm{VP}_{2}$ & $\mathrm{C}_{1} / \mathrm{C} 6^{\mathrm{c}}$ & Fever, rash, vesicles, diarrhoea & Unknown \\
\hline $16-12$ & $<6$ months & Stool & $\mathrm{VP}_{1}$ & $\mathrm{C}_{1}$ & Fever $>38.5^{\circ} \mathrm{C}$, rash & 4 days \\
\hline $16-13$ & $<6$ months & Stool & $\mathrm{VP}_{1}, \mathrm{VP}_{2}$ & $\mathrm{C}_{1}$ & Unknown & Unknown \\
\hline $16-14$ & $<6$ months & Stool & $\mathrm{VP}_{2}$ & $\mathrm{C}_{1} / \mathrm{C}^{\mathrm{c}}$ & $\begin{array}{l}\text { Fever }>38.5^{\circ} \mathrm{C} \text {, group B } \\
\text { Streptococcus sepsis }\end{array}$ & 10 days \\
\hline $16-15$ & $<6$ months & Stool & $\mathrm{VP}_{2}$ & $\mathrm{C}_{1}$ & Fever & 7 days \\
\hline $16-16$ & $<6$ months & Stool & $\mathrm{VP}_{1}$ & $\mathrm{C} 6$ & Fever $>38.5^{\circ} \mathrm{C}$, vomiting, sepsis & 4 days \\
\hline $16-17$ & $<6$ months & Stool & $\mathrm{VP}_{2}$ & $\mathrm{C}_{1} / \mathrm{C} 6^{\mathrm{c}}$ & Unknown & Unknown \\
\hline $16-18$ & $1-2$ years & Vesicular fluid & $\mathrm{VP}_{2}$ & $\mathrm{C}_{1}$ & Unknown & Unknown \\
\hline $16-19$ & $25-30$ years & Vesicular fluid & $\mathrm{VP}_{2}$ & $\mathrm{C}_{1}$ & Unknown & Unknown \\
\hline $16-20$ & $1-2$ years & Stool & $\mathrm{VP}_{2}$ & $\mathrm{C}_{2}$ & Unknown & Unknown \\
\hline
\end{tabular}

HFMD: hand, foot, and mouth disease.

${ }^{a}$ VP1: sequence was obtained from VP1 PCR; VP2: sequence was obtained from VP2 PCR; WGS: sequence was obtained from whole genome sequencing.

${ }^{\text {b }}$ Grouping with $\mathrm{C} 6$ in near-complete genome analysis, but not with $\mathrm{C} 6$ or $\mathrm{C}_{1}$ in VP1 analysis. ${ }^{\text { }} \mathrm{Grouping}$ with $\mathrm{C} 6$ when analysing the VP1 region, but no complete genome sequence available and therefore not possible to confidently assign as C6. 
authors propose that these new variants are seen as a new genotype, $\mathrm{C} 6$, rather than a lineage of $\mathrm{C}_{1}$.

Both German and Danish new variants appear to be recombinant forms, with 3 Dpol regions of separate origins. This was previously described for the German strains [6]. In fact, both the German and Danish strains appear to be mosaic, a result of several recombination events throughout the genome. The co-circulation of multiple genotypes of EV-A71 in one country during a single season/year, as demonstrated in this study, provides the environment for the appearance of future novel recombinant variants.

EV-A71 genotype $C_{4}$ subtypes associated with more severe clinical outcomes than other EV-A71 genotypes and subtypes have previously been described $[3,4]$. The new C variant was described as emerging in 2015 in Germany and associated with rhomboencephalitis/ brainstem encephalitis and severe neurological and cardiopulmonary complications [5,6,14]. However, the collection of samples for the EV surveillance system, as in the case of Denmark and Germany, may introduce a bias in this regard. The new EV-A71 genotype $C$ variant identified in Denmark in 2016, was associated with both neurological symptoms and HFMD, illustrating the ability of EVs to cause a wide range of symptoms with rare cases of severe complications.

New emerging EVs have already demonstrated their potential to cause devastating epidemics such as the major EV-A71 epidemics in Asia and South Pacific Region. There is therefore a need to detect and monitor these viruses closely. In addition to detection and reporting of an emerging new EV-A71 recombinant virus, a proposed genotype $\mathrm{C} 6$, this study demonstrates important challenges in detection as well as characterisation of emerging EV infections. Current state-of-the-art EV PCR-based methods continuously need to undergo evaluation to ensure that primers for diagnostics, as well as typing, maintain the ability to detect and fully classify new EV variants beyond the (sero)type level. PCR-based typing relies on the amplification of short genome fragments, and as a consequence may not only result in missed detection of new genotypes, but also in misclassification due to a lack of appropriate reference sequences. Furthermore, timely and public sharing of whole EV genome sequence data are essential for detection of new variants.

The possible severity of EV-A71 infections together with the continuing evolution and appearance of new EV-A71 genotypes, as well as other emerging EV causing neurological disease, underscores the importance and relevance to prioritise strengthening of EV surveillance globally.

\section{Acknowledgements}

We wish to thank Bente Andersen for Laboratory assistance, and Palle Valentiner-Brandt for help with accessing clinical information. We also wish to thank all the clinical microbiology departments in Denmark for their continued support and participation in the polio and non-polio enterovirus surveillance system.

\section{Conflict of interest}

None declared.

\section{Authors' contributions}

SOI: conceptualised the study in collaboration with THF, was involved with the design of the study, drafted the manuscript and conducted the phylogenetic analyses.

AGN: carried out part of the pilot study of next generation sequencing of enteroviruses, identified the first novel recombinant, and has critically reviewed the manuscript.

RATR: was involved with the design of the study, and has contributed to the writing of the manuscript.

MWP: conducted the laboratory characterisation of enteroviruses, and has critically reviewed the manuscript.

PEA: responsible for the collection of clinical information for the Danish enterovirus surveillance system, and has critically reviewed the manuscript.

TKF: conceptualised the study in collaboration with SOI, and has contributed to the writing of the manuscript.

\section{References}

1. Badran SA, Midgley S, Andersen P, Böttiger B. Clinical and virological features of enterovirus 71 infections in Denmark, 2005 to 2008.Scand J Infect Dis. 2011;43(8):642-8. DOI: 10.3109/00365548.2011.577094 PMID: 21526904

2. Fischer TK, Nielsen AY, Sydenham TV, Andersen PH, Andersen $\mathrm{B}$, Midgley SE. Emergence of enterovirus $71 \mathrm{C} 4 \mathrm{a}$ in Denmark, 2009 to 2013. Euro Surveill. 2014;19(38):20911. DOI: 10.2807/1560-7917.ES2014.19.38.20911 PMID: 25306878

3. Zhang Y, Tan X, Cui A, Mao N, Xu S, Zhu Z, et al. Complete genome analysis of the $\mathrm{C}_{4}$ subgenotype strains of enterovirus 71: predominant recombination $\mathrm{C}_{4}$ viruses persistently circulating in China for 14 years. PLoS One. 2013;8(2):e56341. DOI: 10.1371/journal.pone.0056341 PMID: 23441179

4. Liu Y, Fu C, Wu S, Chen X, Shi Y, Zhou B, et al. A novel finding for enterovirus virulence from the capsid protein VP1 of EV71 circulating in mainland China. Virus Genes. 2014;48(2):260-72. DOI: $10.1007 / \mathrm{S} 11262-014-1035-2$ PMID: 24442718

5. Böttcher S, Obermeier PE, Neubauer K, Diedrich S, Laboratory Network for Enterovirus Diagnostics. Recombinant Enterovirus A71 Subgenogroup C1 Strains, Germany, 2015.Emerg Infect Dis. 2016;22(10):1843-6. DOI: 10.3201/eid2210.160357 PMID: 27439117

6. Karrasch M, Fischer E, Scholten M, Sauerbrei A, Henke A, Renz $\mathrm{DM}$, et al. A severe pediatric infection with a novel enterovirus A71 strain, Thuringia, Germany. J Clin Virol. 2016;84:90-5. DOI: 10.1016/j.jcv.2016.09.007 PMID: 27771495

7. Condell O, Midgley S, Christiansen CB, Chen M, Chen Nielsen $X$, Ellermann-Eriksen S, et al. Evaluation of the enterovirus laboratory surveillance system in Denmark, 2010 to 2013. Euro Surveill. 2016;21(18):30218. DOI: 10.2807/1560-7917. ES.2016.21.18.30218 PMID: 27173593

8. Nasri D, Bouslama L, Omar S, Saoudin H, Bourlet T, Aouni $M$, et al. Typing of human enterovirus by partial sequencing of VP2. J Clin Microbiol. 2007;45(8):2370-9. DOI: 10.1128/ JCM.00093-07 PMID: 17537940

9. Nix WA, Oberste MS, Pallansch MA. Sensitive, seminested PCR amplification of VP1 sequences for direct identification of all enterovirus serotypes from original clinical specimens.J Clin 
Microbiol. 2006;44(8):2698-704. DOI: 10.1128/JCM.00542-06 PMID: 16891480

10. Fonager J, Stegger M, Rasmussen LD, Poulsen MW, Rønn J, Andersen PS, et al. A universal primer-independent next-generation sequencing approach for investigations of norovirus outbreaks and novel variants. Sci Rep. 2017;7(1):813. DOI: 10.1038/s41598-017-00926-x PMID: 28400558

11. Simmonds P. SSE: a nucleotide and amino acid sequence analysis platform.BMC Res Notes. 2012;5(1):50. DOI: 10.1186/1756-0500-5-50 PMID: 22264264

12. Tamura K, Stecher G, Peterson D, Filipski A, Kumar S. MEGA6: Molecular Evolutionary Genetics Analysis version 6.0.Mol Bio Evol. 2013;30(12):2725-9. DOI: 10.1093/molbev/mst197 PMID: 24132122

13. Lole KS, Bollinger RC, Paranjape RS, Gadkari D, Kulkarni SS, Novak NG, et al. Full-length human immunodeficiency virus type 1 genomes from subtype C-infected seroconverters in India, with evidence of intersubtype recombination. J Virol. 1999;73(1):152-60.PMID: 9847317

14. Antona D, Kossorotoff M, Schuffenecker I, Mirand A, LeruezVille $M$, Bassi $C$, et al. Severe paediatric conditions linked with EV-A71 and EV-D68, France, May to October 2016

Euro Surveill. 2016;21(46):30402. DOI: 10.2807/1560-7917.

ES.2016.21.46.30402 PMID: 27918268

\section{License and copyright}

This is an open-access article distributed under the terms of the Creative Commons Attribution (CC BY 4.0) Licence. You may share and adapt the material, but must give appropriate credit to the source, provide a link to the licence, and indicate if changes were made.

This article is copyright of the authors, 2017. 